\title{
Endometrial Carcinoma and Bisphenol A: A Pilot Case-Control Study
}

\author{
Carmen Imma Aquino ${ }^{1}$, Jacopo Troisi ${ }^{1,2,3}$, Antonio D'Antonio ${ }^{1}$, Luigi Giugliano ${ }^{1}$, Antonio \\ Raffone $^{4}$, Laura Sarno ${ }^{4 *}$, Gabriele Saccone ${ }^{4}$, Giovanni Scala ${ }^{2}$ and Maurizio Guida ${ }^{1,2}$ \\ ${ }^{1}$ Department of Medicine and Surgery and Dentistry, "Scuola Medica Salernitana", University of Salerno, Italy \\ ${ }^{2}$ Theoreo srl - Spin-off company of the University of Salerno, Italy \\ ${ }^{3}$ European Biomedical Research Institute of Salerno (EBRIS), Via S. De Renzi, 50, 84125 Salerno (Italy) \\ ${ }^{4}$ Department of Neurosciences and Reproductive and Dentistry Sciences, University of Naples Federico II, Naples (Italy) \\ *Corresponding author: Laura Sarno, Department of Neuroscience, Reproductive Sciences and Dentistry, School of Medicine, \\ University of Naples "Federico II", Naples, Italy
}

\section{ARTICLE INFO \\ Received: 幽 September 24, 2019 \\ Published: 幽 October 01, 2019}

Citation: Aquino $\mathrm{CI}$, et al. Endometrial Carcinoma and Bisphenol A: A Pilot CaseControl Study. Biomed J Sci \& Tech Res 21(4)-2019. BJSTR. MS.ID.003641.

Keywords: Endometrial Cancer; Bisphenol A; Endocrine Disruptors; Hyperestrogenism

\section{ORCID IDs}

Carmen Imma Aquino

http://orcid.org/0000-0002-4797-6161

Jacopo Troisi

https://orcid.org/0000-0003-2962-7379

Antonio D’Antonio

https://orcid.org/0000-0001-5425-6878

Antonio Raffone

https://orcid.org/0000-0001-5443-2333

Laura Sarno

http://orcid.org/0000-0002-5578-2885

Gabriele Saccone

http://orcid.org/0000-0003-0078-2113

Maurizio Guida

http://orcid.org/0000-0001-7372-0680
ABSTRACT

Aim: Endometrial cancer evolves from a hyperestrogenic pattern. Bisphenol A (BPA) can act as estrogen-mimetic at low doses. The aim of this pilot observational case-control study is to evaluate the possible hormone-dependent effects of BPA in endometrial cancer.

Methods: Biological samples from seventeen women affected by endometrial cancer and seven controls affected by benign uterine disease were collected. Two aliquots of $0.5 \mathrm{~mL}$ or $25 \mathrm{mg}$ were taken from each blood, urine or tissue sample, one for total BPA measurement (free BPA plus BPA glucuronide and sulfate), and one for free BPA.

Results: The concentration of BPA in blood and urine was higher in cases, while BPA concentration at uterine level was higher in controls. In the blood, higher BPA concentrations were found in cases compared to controls for free BPA $(0.59 \pm 0.19$ Vs $0.54 \pm 0.12)$, BPA conjugate $(1.43 \pm 0.26$ Vs $0.94 \pm 0.18)$ and total BPA $(2.01 \pm 0.31$ Vs $1.48 \pm 0.22$ ), though not statistically significant. Similarly, in urine higher free BPA $(2.00 \pm 0.84$ Vs $1.56 \pm 0.34, \mathrm{p}<0.001)$, conjugated BPA (4.33 \pm 1.29 Vs $2.98 \pm 0.82, \mathrm{p}<0.05)$ and total BPA $(6.34 \pm 1.38$ Vs $4.54 \pm 0.65, \mathrm{p}<0.01)$ concentrations were found in cases compared to controls. In uterine samples, free BPA, conjugated BPA and total BPA were lower in cases than controls $(0.03 \pm 0.01$ Vs $0.10 \pm 0.03, \mathrm{p}<0.001 ; 0.06 \pm 0.01$ Vs $0.17 \pm 0.06$, $\mathrm{p}<0.001$ and $0.08 \pm 0.01$ Vs $0.26 \pm 0.08, \mathrm{p}<0.001$, respectively).

Conclusion: Evaluating our results in the perspective of the literature, we hypothesized that BPA could induce an indirect abnormal cell proliferation at the uterine level. It probably acts as an hyperestrogenic central trigger, through a possible exacerbation of the action of the well-known risk factors . More studies are necessary to understand the mechanisms at the bases of the described process. 


\section{Introduction}

Female cancers represent one of the major causes of morbidity and mortality in the adult population. Scientific research has allowed a significative increase in the early diagnosis for some of them (e.g. cervical cancer) but not for all, as for the endometrial neoplasia. Endometrial cancer is the fifth most common malignant tumor of the female reproductive tract in developed countries $[1,2]$. It represents about $5 \%$ of the total female tumors, with an incidence ranging from 3\% among women below 49 years old to $7 \%$ in women between $50-69$ years old [3]. In $90 \%$ of cases, endometrial cancer is sporadic, the remaining $10 \%$ is hereditary [4]. The observed racial and geographic differences suggest that the onset of endometrial cancer is strictly affected by genetic and environmental elements. In about $80 \%$ of these conditions, hyperestrogenism plays a key role [5]. Nowadays, the American College of Obstetricians and Gynecologists underlines that we don't have non-invasive cost-benefit diagnostic methods of screening for asymptomatic endometrial carcinoma. When indicated, the diagnostic route involves ultrasonography and biopsy hysteroscopy [6].

More innovative techniques have been proposed, such as: recent metabolic test, multidepth genetic sequencing, and evaluation of small non-coding miRNAs (sncRNAs) and long non-coding RNAs (Ing RNAs) [7,8]. However, these techniques are not routinely used yet. Of the two types of endometrial cancer, type 2 endometrial cancer develops mostly from atrophic endometrium, is rarer and appears to be less associated with anovulation, infertility, obesity or diabetes mellitus; while risk factors mostly concern type 1 , which is more related to estrogens effects. Several risk factors for type 1 were reported: reproductive, metabolic, genetic, hormonal [9-16]. Among the hormonal risk factors, scientific evidences suggest that the so-called "endocrine disruptors", such as Bisphenol A (BPA), should be included [17-19]. Endocrine or xenormon disruptors are exogenous chemicals that mimic or antagonize hormonal biological activity [20]. For many years, endocrine disruptors have been studied for possible obstetric and pediatric complications [21,22]. As illustrated, direct or indirect estrogenic action of BPA could favor the hormonal dysregulation at the base of the endometrial neoplasm and/or contribute to proliferation, for example as the proven effects on neoangiogenesis and/or acting on epidermal growth factor (EGF) and/or on microRNAs (miRNAs) regulation [17,21,23-28].

Starting from the knowledge that endometrial cancer evolves from a hyperestrogenic pattern and given the estrogen-mimetic action of BPA, our study aimed to formulate some hypothesis of this mechanism of action, eventually correlated with endometrial carcinogenesis [29]. Considering that the literature describes extensively the hyperestrogenism at the basis of the most common type 1 endometrial carcinoma, it is interesting to look at the effects of the hormone-stimulating factors present in our daily life. In these recent years, the attention of the social media has been constantly focused on environmental pollution. Our research has been addressed to BPA, to which we are exposed frequently and in an underhand way. Despite there are protective European laws, exposure to BPA is really ubiquitous and every woman in her life experiences more or less massive contact [30]. Serum concentration of BPA has been documented to be $0.2 \mathrm{ng} / \mathrm{ml}(0.1-10 \mu \mathrm{mol} / \mathrm{l})$ in the general population, with possible negative effects on human health even at low doses [27] [31]. Thus, aim of this observational, longitudinal, prospective, case-control study is to report the BPA concentrations in urine blood and uterine samples of patients affected by endometrial cancer (type 1) and to compare them to those of patients affected by benign uterine conditions.

\section{Materials and Methods}

\section{Study Design and Study Population}

This is a case-control prospective study performed at University of Salerno from December 2016 to May 2017.

We screened all the patients referred to our hospital due to metrorrhagia or with the following criteria: women between 50 and 80 years old, being in menopause, overweight or obese (Body Mass Index $>25$ ), with a familiarity for uterus, breast or ovarian cancer. Diagnosis of endometrial cancer was performed by transvaginal ultrasound, followed by office hysteroscopy and endometrial biopsy, in case of abnormal ultrasound findings (i.e. thickening and endometrial heterogeneity). All the patients with a diagnosis of endometrial cancer were included as cases. Cases were compared to a control group (CTRLs) of patients affected by benign uterine conditions, such as uterine myoma or simple endometrial hyperplasia without atypia, that had an indication for hysterectomy. All the diagnosis were confirmed via histological examination performed by the Pathological Anatomy Unit of S. Giovanni di Dio e Ruggi D'Aragona Hospital, according to the criteria of the World Health Organization. The oncologic staging was defined according to the criteria of the International Federation of Gynecology and Obstetrics [32]. The enrollment was proposed during preoperative examinations. All the included patients signed a written consent form. The study was approved by the Ethical Committee of University of Salerno ASL Napoli3Sud, prot.91/2016. At enrollment, demographic, clinical, anthropometric and anamnestic data were collected and recorded on a dedicated database.

\section{Sample Collection}

Human tissue collection strictly adhered to the guidelines outlined in the Declaration of Helsinki IV edition.

We collected a blood and urine sample for each included patient. Blood samples were collected immediately before surgery from an antecubital vein, using a BD vacutainer (Becton Dickinson, Oxfordshire, UK) blood collection red tube (with no additives). After centrifugation for $20 \mathrm{~min}$ at $3000 \mathrm{rpm}$, the serum was collected in a sterilized Eppendorf Lock Tube and immediately frozen to $-80^{\circ} \mathrm{C}$ until the time of analysis. All patients were asked to respect a 
12-hours fast before blood collection. A sample of urine mid-stream was collected in a screw-top container and frozen at $-80^{\circ} \mathrm{C}$. During the surgical treatment, a small endometrial sample (about $0.5 \mathrm{~cm}$ of length) was collected by a cold blade, taken and immediately inserted into the vacuum and sterilized Eppendorf Lock Tube. In detail, a macroscopically healthy endometrial sample was taken for both the cases and the controls, while from the cases was also taken a macroscopically pathological sample. In all the cases, there was histological confirmation afterwards. All the tubes were frozen at $-80{ }^{\circ} \mathrm{C}$ until the time of the analysis.

\section{BPA Analysis}

The determination of free BPA and its conjugated metabolite was obtained as described by Kosarac et al., with some minor changes [33]. Two aliquots of $0.5 \mathrm{~mL}$ or $25 \mathrm{mg}$ were obtained from each serum, urine or tissue sample respectively, one for total BPA determination (free BPA plus BPA glucuronide and sulfate), and one for the determination of free BPA. BPA conjugate range was deduced from the difference between the two determinations. For free BPA calculation, $20 \mu \mathrm{l}$ of d16-BPA at a concentration of $100 \mu \mathrm{g} / \mathrm{L}, 1 \mathrm{~mL}$ of a saturated solution of $\left(\mathrm{NH}_{4}\right)_{2} \mathrm{SO}_{4}, 2 \mathrm{~mL}$ of ethanol and $4 \mathrm{~mL}$ of hexane were added. These substances were then vortex agitated for $30 \mathrm{~s}$ and then left at rest to permit the two phases to separate from each other. The upper organic phase was eliminated. The nonpolar phase was further defatted with $4 \mathrm{~mL}$ of hexane. After another utilization of vortex, separating the two phases left and eliminating the non-polar phase, $3 \mathrm{~mL}$ of dichloromethane were added. The sample, agitating again for $30 \mathrm{~s}$, was sonicated at $30{ }^{\circ} \mathrm{C}$ for $10 \mathrm{~min}$. The lower organic phase was inserted into a new vial, the solvent removed by a stream of nitrogen in a water bath at $40{ }^{\circ} \mathrm{C}$ and the sample reconstituted with $2 \mathrm{~mL}$ of ultrapure water grade.

The extracted sample was purified in two successive SPE steps, one with a Florisil solid phase and the other with a C18 solid phase. The Florisil column $(1 \mathrm{~g}, 6 \mathrm{~mL})$ was conditioned with $10 \mathrm{~mL}$ of dichloromethane followed by $10 \mathrm{~mL}$ of hexane and the extracted sample $(2 \mathrm{~mL})$ was loaded. Ten $\mathrm{mL}$ of hexane were eluted (this fraction containing fatty residue was removed), then the BPA was eluted with $25 \mathrm{~mL}$ of di-chloromethane. The sample collected was brought to dryness with a stream of nitrogen in a bath at $40{ }^{\circ} \mathrm{C}$ and then reconstituted with $3 \mathrm{~mL}$ of ultrapure water. In the second step, the C18 SPE cartridge $(0.5 \mathrm{~g}, 6 \mathrm{~mL})$ was conditioned with $9 \mathrm{~mL}$ of acetone, $9 \mathrm{~mL}$ of methanol and $5 \mathrm{~mL}$ of ultrapure water. After loading the $3 \mathrm{~mL}$ of sample, the column was dried under vacuum and then eluted with $6 \mathrm{~mL}$ of methanol followed by $5 \mathrm{~mL}$ of acetone. The eluate was dried in a stream of nitrogen in a bath at $40{ }^{\circ} \mathrm{C}$ and dissolved in $50 \mu \mathrm{l}$ of pyridine. Fifty $\mu \mathrm{L}$ of BSTFA were added for the derivatization and the reaction was conducted for $4 \mathrm{~h}$ at $70^{\circ} \mathrm{C}, 1 \mu \mathrm{l}$ of derivatized sample was then analyzed by GC-MS/MS. The deconjugation reaction was carried out on an aliquot of $0.5 \mathrm{~mL}$ of sample.

Before the enzymatic process, $20 \mu \mathrm{L}$ of d16-BPA at a concentration of $100 \mu \mathrm{g} / \mathrm{L}$ were utilized as an internal standard.
Then $50 \mu \mathrm{l}$ of -glucuronidase/sulfatase (4414/168 U/L) were added; the deconjugation reaction was carried out for $3 \mathrm{~h}$ in a shaking water bath at $37^{\circ} \mathrm{C}$. After the hydrolysis, $100 \mu \mathrm{L}$ of $2 \mathrm{~N} \mathrm{HCl}$ were added to deactivate the enzymes and the BPA was extracted and purified in the same modality as free BPA. The instrumental analysis method is based on a gas chromatographic column Supleco SLB-5 ms with a length of $10 \mathrm{~m}$ and an internal diameter of $0.1 \mathrm{~mm}$, with a film thickness of $0.1 \mu \mathrm{m}$. The GC oven program is based on an initial phase of $1.5 \mathrm{~min}$ at $160^{\circ} \mathrm{C}$ and two ramps: the first at $20^{\circ} \mathrm{C} /$ $\min$ up to $260^{\circ} \mathrm{C}$, the second at $40^{\circ} \mathrm{C} / \mathrm{min}$ up to $320^{\circ} \mathrm{C}$; the injection temperature was set at $260^{\circ} \mathrm{C}$ and the linear velocity of the carrier gas (He) was $70 \mathrm{~cm} / \mathrm{s}$. This method needs a first pressure of $654 \mathrm{kPa}$ and a linear flow of $1.12 \mathrm{~mL} / \mathrm{min}$.

The total analytical time is $8 \mathrm{~min}$, these fast analyses need high-speed data acquisition. Our laboratory used two acquisition channels, one in SCAN mode be-tween $\mathrm{m} / \mathrm{z}=50$ and $\mathrm{m} / \mathrm{z}=500$ and one in MRM mode: $357.10>191.20 \mathrm{~m} / \mathrm{z}$ for BPA and $370.50>$ $73.10 \mathrm{~m} / \mathrm{z}$ for the $\mathrm{d} 16-\mathrm{BPA}$. The event time for the SCAN mode was set to $0.07 \mathrm{~s}$ (corresponding to a scan speed of $10,000 \mathrm{amu} / \mathrm{s}$, the maximum obtainable using the TQ-8030). Calibration was obtained using nine standard solutions and a blank. The standard ranged from $0.01 \mu \mathrm{g} / \mathrm{L}$ up to $100 \mu \mathrm{g} / \mathrm{L}$ and each standard was evaluated in triplicate. Two recovery tests were conducted at 0.5 and at $80 \mu \mathrm{g} / \mathrm{L}$, showing a recovery of $79 \%$ at low concentration level and $85 \%$ at high concentration, according to Kosarac et al. [33]. The results were corrected according to the nearest recovery value. Quantization was obtained with the isotopic dilution method using d16-BPA as an internal standard. Every 10 samples, a blank sample and two calibration solutions: $25 \mu \mathrm{g} / \mathrm{L}$, and $0.01 \mu \mathrm{g} / \mathrm{L}$ were analyzed. The tolerance criteria adopted were $<$ LOQ for blank, $\pm 30 \%$ for the solution of $0.01 \mu \mathrm{g} / \mathrm{L}$ and $\pm 10 \%$ for the $25 \mu \mathrm{g} / \mathrm{L}$.

\section{Statistical Analysis}

Statistical analysis was performed using Statistica software (StatSoft, Oklahoma, USA) and Minitab (Minitab Inc, Pennsylvania, USA). Data were reported as number (percentage) for categorical variables and median (interquartile range) for continuous variables. The comparison between groups was made with the Rank Sum Test according to Mann-Whitney or by means of analysis of variance on rank preformed single way (according to Kruskal-Wallis), also using the post hoc test of Dunn. The normal distribution of data was verified using the Shapiro-Wilks test. The alpha value was set to 0.05 .

\section{Results}

We screened 150 patients at risk of endometrial cancer from December 2016 to May 2017. Fifty-one (34\%) showed abnormal ultrasound findings (i.e. thickening and endometrial heterogeneity), for which it was suggested to perform an office hysteroscopy. This outpatient procedure allowed the identification of 17 cases of endometrial cancer, as confirmed by a separate trained pathologist. Seven controls were enrolled among women affected by benign 
uterine conditions, (6 uterine myomas and one simple endometrial hyperplasia without atypia). Patients' characteristics are reported in Table 1. Cases and CTRLs were similar for age (59 (56-69) vs 57(50-61)) years old and BMI (31 (29-36) vs 30 (27.5-30.5) kg/ $\mathrm{m} 2$ ). The mean average of children for each patient is 2.BPA values in both groups are reported in Table 2. The concentration of BPA in blood and urine was higher in cases, while BPA concentration at uterine level was higher in controls.

Table 1: Patients' characteristics.

\begin{tabular}{|c|c|c|}
\hline & $\begin{array}{c}\text { Endometrial cancer } \\
\text { patients }\end{array}$ & Controls \\
\hline Number of cases & 17 & 7 \\
\hline Age (years) [median (IQR)] & $59(56-69)$ & $57(50-61)$ \\
\hline Weight (Kg) [median (IQR)] & $80(74-91)$ & $75(70-79)$ \\
\hline Height (cm) [median (IQR)] & $1.6(1.57-1.60)$ & $1.6(1.58-1.60)$ \\
\hline BMI (Kg/m2) [median (IQR)] & $31(29-36)$ & $30(27.5-30.5)$ \\
\hline $\begin{array}{l}\text { Impaired fasting glucose or } \\
\text { Diabetes }\end{array}$ & $8(47.1 \%)$ & $2(28.6 \%)$ \\
\hline Hypertriglyceridemia & $4(23.5 \%)$ & $1(14.3 \%)$ \\
\hline Hypercholesterolemia & $9(52.9 \%)$ & $3(42.9 \%)$ \\
\hline Metabolic syndrome & $9(52.9 \%)$ & $2(28.6 \%)$ \\
\hline \multicolumn{3}{|c|}{ Grade } \\
\hline G1 & $4(23.5 \%)$ & ND \\
\hline G2 & $12(70.6 \%)$ & ND \\
\hline G3 & $1(6.1 \%)$ & ND \\
\hline \multicolumn{3}{|c|}{ Stage } \\
\hline I & $13(76.5 \%)$ & ND \\
\hline II & $1(6.1 \%)$ & ND \\
\hline III & $3(17.6 \%)$ & ND \\
\hline
\end{tabular}

In the blood, higher BPA concentrations were found in cases compared to controls for free BPA $(0.59 \pm 0.19$ Vs $0.54 \pm 0.12)$, BPA conjugate $(1.43 \pm 0.26$ Vs $0.94 \pm 0.18)$ and total BPA $(2.01 \pm 0.31$ Vs $1.48 \pm 0.22$ ), even if the difference was not statistically significant, maybe due to the small sample size of the study. Similarly, in urine higher BPA concentrations were found in cases compared to controls, considering free BPA $(2.00 \pm 0.84$ Vs $1.56 \pm 0.34, \mathrm{p}<0.001)$, conjugated BPA $(4.33 \pm 1.29$ Vs $2.98 \pm 0.82, \mathrm{p}<0.05)$ and total BPA $(6.34 \pm 1.38$ Vs $4.54 \pm 0.65, p<0.01)$. In uterine samples, free $B P A$, conjugated BPA and total BPA were lower in cases than controls $(0.03 \pm 0.01$ Vs $0.10 \pm 0.03, p<0.001 ; 0.06 \pm 0.01$ Vs $0.17 \pm 0.06$, $\mathrm{p}<0.001$ and $0.08 \pm 0.01$ Vs $0.26 \pm 0.08, \mathrm{p}<0.001$, respectively). We calculated the endometrium/urine BPA ratios in order to compare BPA concentration at uterine level and in urine; as shown in Table 2 and in Figure 1, it was lower in cases compared to CTRLs (free BPA $6.16 \pm 1.87$ vs $1.35 \pm 0.61$; conjugate $B P A 5.70 \pm 1.53$ vs $1.36 \pm 0.63$; total BPA 5.81 \pm 1.54 vs $1.30 \pm 0.53$; $\mathrm{p}<0.001$ ).

Table 2: Bisphenol A (BPA) concentration in blood, urine and tissue samples.

\begin{tabular}{|c|c|c|c|}
\hline & & $\begin{array}{c}\text { Controls } \\
\text { (CTRL) } \\
(\mathrm{n}=7)\end{array}$ & $\begin{array}{c}\text { Endometrial } \\
\text { cancers } \\
\text { patients (KE) } \\
(n=17)\end{array}$ \\
\hline \multirow[t]{3}{*}{ Blood } & Free BPA (ng/mL) & $0.54 \pm 0.12$ & $0.59 \pm 0.19$ \\
\hline & $\begin{array}{c}\text { Conjugate BPA } \\
\text { (ng/mL) }\end{array}$ & $0.94 \pm 0.18$ & $1.43 \pm 0.26$ \\
\hline & Total BPA (ng/mL) & $1.48 \pm 0.22$ & $2.01 \pm 0.31$ \\
\hline \multirow[t]{3}{*}{ Urine } & Free BPA (ng/mL) & $1.56 \pm 0.34$ & $2.00 \pm 0.84^{* * *}$ \\
\hline & $\begin{array}{c}\text { Conjugate BPA } \\
(\mathrm{ng} / \mathrm{mL})\end{array}$ & $2.98 \pm 0.82$ & $4.33 \pm 1.29^{*}$ \\
\hline & Total BPA (ng/mL) & $4.54 \pm 0.65$ & $6.34 \pm 1.38^{* *}$ \\
\hline \multirow[t]{3}{*}{ Endometrium } & Free BPA $(\mathrm{ng} / \mathrm{mL})$ & $0.10 \pm 0.03$ & $0.03 \pm 0.01^{* * *}$ \\
\hline & $\begin{array}{c}\text { Conjugate BPA } \\
\text { (ng/mL) }\end{array}$ & $0.17 \pm 0.06$ & $0.06 \pm 0.01^{* * *}$ \\
\hline & Total BPA (ng/mL) & $0.26 \pm 0.08$ & $0.08 \pm 0.01^{* * *}$ \\
\hline \multirow[t]{3}{*}{$\begin{array}{c}\text { Endometrium/ } \\
\text { Urine }\end{array}$} & Free BPA $(\mathrm{ng} / \mathrm{mL})$ & $6.16 \pm 1.87$ & $1.35 \pm 0.61^{* * *}$ \\
\hline & $\begin{array}{c}\text { Conjugate BPA } \\
\text { (ng/mL) }\end{array}$ & $5.70 \pm 1.53$ & $1.36 \pm 0.63^{* * *}$ \\
\hline & Total BPA $(\mathrm{ng} / \mathrm{mL})$ & $5.81 \pm 1.54$ & $1.30 \pm 0.53^{* * *}$ \\
\hline
\end{tabular}
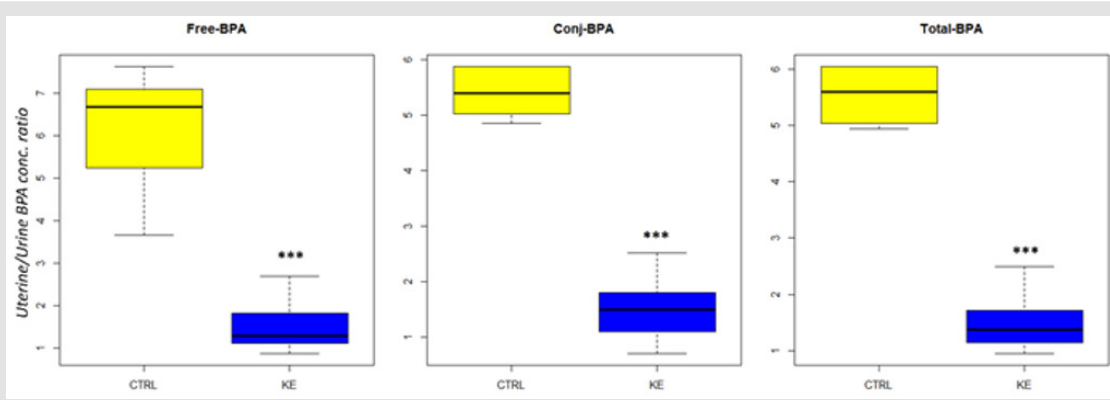

Figure 1: Endometrium/Urine BPA concentration ratio. ${ }^{* *}$ indicates a p-value $<0.001$.

\section{Discussion}

Our pilot study tried to evaluate the correlation between BPA and endometrial cancer through measurements of the endocrine disruptor in blood, urine and uterine samples as sensitive index of the exposure. Aim of this study was to begin understanding the role played by BPA in carcinogenesis and tumor progression, evaluating also the future therapeutic potential and the ability to prevent endometrial carcinoma. We found higher concentration of 
free, conjugated and total BPA in urine and blood samples of cases compared to controls and surprisingly lower concentrations of this endocrine disruptor in uterine samples of cases compared to controls. Given the estrogen-mimetic action of BPA and the wellknown hyperestrogenism present in type 1 endometrial carcinoma, the first hypothesized result included a general increase of the endocrine disruptor in all biological samples of cases.

To understand our results, it should be noted that unbound (free) BPA represents the active portion, while the conjugated BPA, mirror of the metabolic capacity of the endocrine interferent, represents the inactive portion from the point of view of its endocrine activity. The two metabolites, BPA-glucuronidate and BPA-sulphate, do not alter the biological processes of the organism; conversely, BPA unmodified in inactive metabolites binds to plasma proteins and interferes with biological processes [18]. Contrary to what has been described in literature for other pathological effects (for example, fetal malformations) [22], the evaluation of the percentage of conjugated BPA (Table 2) in the analyzed biological samples was probably not correlated with the condition of "poor metabolizer" but with a direct proportionality to environmental exposure, complicating the concept of a predisposing metabolic susceptibility for tumorigenesis in some women compared to others. The results of our research find supporting elements in scientific works conducted in vitro [17], on animals [19][34] and on humans [18].

Aghanova et al. analyzed human endometrial fibroblasts, finding that BPA was significantly lower in oncologic endometrial samples than in the benign ones [17]. This was explained by the fact that at significant exposures ( $>50 \mu \mathrm{mol} / \mathrm{L})$ BPA decreases the expression of stromal endometrial fibroblasts, with direct action on the mRNA expression of P450scc (enzyme that converts cholesterol into pregnenolone), even promoting a decidual endometrial phenotype [17]. However, Pollock et al. put a low dose of radioactive BPA in food of female mice, whose measurement at uterine level after 24 hours showed a significant amount of the endocrine disruptor [19]. After administering BPA and estradiol at the same time, however, the level of uterine BPA decreased significantly with respect to the assumption of BPA alone. The murine experiments of Pollock et al. showed an initial greater distribution of BPA in the major organs, glands and reproductive tissues, where $\operatorname{ER} \alpha$ and $\operatorname{ER} \beta$ are widely represented: however, BPA concentrations result decreased at uterine level after administration of estradiol [19].

One of the most plausible hypotheses that Pollock at al. used to explain the decreased BPA levels of cases in uterine specimens is related to the 1000 - fold greater estrogenic affinity for receptors compared to BPA. In fact, under hyperestrogenism conditions, estrogen can saturate the uterine receptor structures preventing the binding of the endocrine disruptors [19][25]. Another study, performed on ovariectomized monkeys (Cercopithecus aethiops sabaeus) exposed to BPA, estradiol or a combination of the two, found that in monkeys treated with BPA, estradiol or both (but not in controls) there is an increased endometrial proliferation [34]. The explanation provided by these researchers indicates that BPA together with estrogens could result in an alteration in hormonal balance and an increase in estrogenic response, predominantly in an indirectly way [34].

Finally, considering the possible effects of BPA on endometrium, Hiroi et al. evaluated patients with and without endometrial cancer and found a higher level of BPA in serum but a lower concentration at uterine level in cases than controls. These results suggested, as observed in our study, a complex indirect mode of action of endocrine disrupters in the oncogenesis (Figure 2) [18].

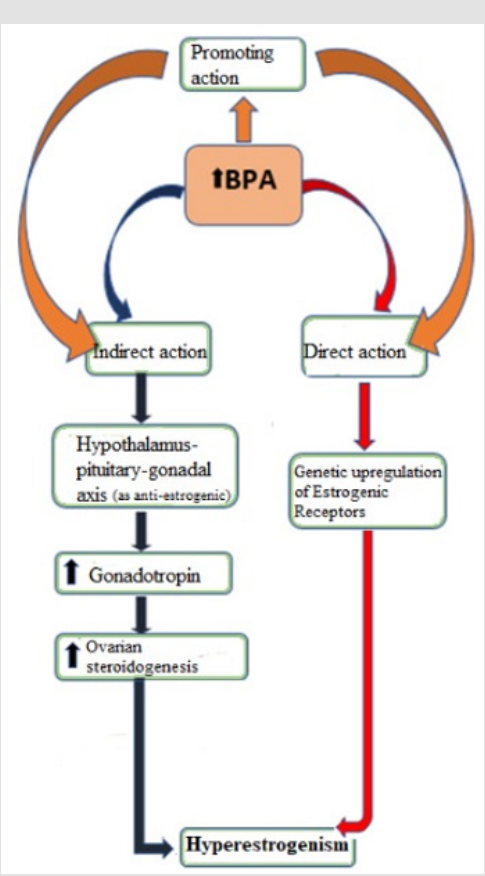

Figure 2: Possible BPA actions as hyperestrogenic promotor. 
This pilot study could be an interesting starter point to consider BPA as potentially related to endometrial tumorigenesis in humans, probably linked to an increased exposure.The main limitation of our study is the small sample size and our results must be confirmed in a larger population. Given the observational nature of our study, we could try to explain the surprising correlations of BPA and endometrial neoplasia thanks also to the assumptions of the literature listed so far. We identified the possible hyperestrogenic behavior of BPA due to a potential promoting action on risk factors, and a direct or an indirect action (Figure 2). For the promoting action, BPA could trigger the vicious cycle of hyperestrogenism acting on the several known risk factors: for example, obesity (with hyperactivity of aromatase) or diabetes (with dysfunctional signaling of insulin), but also acting on hypertension and PCOS $[35,36]$.

The direct route, in which BPA upregulates receptorial genomic domains determining an altered estrogenic balance, appeared to be too simplistic, and may be is not the main hypothesis.The most potentially valid hypothesis could be about an indirect BPA mechanism of action in disrupting the hormonal equilibrium, as seems to be demonstrated in vitro and animals [18,19,37-39]. Moreover, the female reproductive sphere is very articulated: it is also under the control of the central nervous system, that regulates the estrogen-progestin balance by GnRH (Gonadotropin-releasing hormone). Endocrine disruptors (such as BPA) could indirectly influence estrogen-dependent tumorigenesis by acting as trigger on the hypothalamus-pituitary-gonadal axis.

It has been hypothesized that, at the hypothalamus and pituitary level, the excess of circulating BPA may cause central alterations of the gonadotropin secretion feedback [40].

Another possible different mode of action is as an anti-estrogen factor, because of its different behavior depending on tissue [40]: in this way, BPA can increase GnRH and LH secretion (with positive feedback) stimulating ovaries to a steroid hyperproliferation $[18,19,34,41]$.At the uterine level, this excess of estrogen would thus lead to a receptor hyper-saturation that would prevent BPA from occupying the endometrial estrogenic receptors, cause its lower affinity [18,37-39]. Hence, our hypothesis of the "rejected BPA" at endometrial level is the possible explanation of the results of our study. In conclusion, our results want to start focusing on a possible trigger action of BPA in endometrial carcinogenesis as result of environmental exposure. According to this hypothesized theory, BPA could induce an indirect abnormal cell proliferation at the uterine level, maybe acting as hyperestrogenic central trigger, through a possible exacerbation of the action of the well-known risk factors. Other studies are certainly necessary to understand the molecular mechanisms at the bases of the described process. The importance of these informations is related not only to the simple interesting scientific discovery, but also to the indispensable analysis of epidemiological and clinical effects.

\section{References}

1. Ferlay J, Shin H, Bray F, Forman D, Mathers C, et al. (2010) Estimates of worldwide burden of cancer in 2008: GLOBOCAN 2008. International journal of cancer 127(12): 2893-2917.

2. Siegel R, Ward E, Brawley O, Jemal A (2011) Cancer statistics.the impact of eliminating socioeconomic and racial dispari-ties on premature cancer deaths. CA a cancer journal for clinicians 61(4): 212-236.

3. Siegel RL, Miller KD, Jemal A (2017) Cancer statistics. CA a cancer journal for clinicians 67(1): 7-30.

4. Bansal N, Yendluri V, Wenham RM (2009) The molecular biology of endometrial cancers and the implications for pathogenesis, classification, and targeted therapies. Cancer control 16(1): 8-13.

5. Bakkum Gamez JN, Gonzalez Bosquet J, Laack NN, Mariani A, Dowdy SC (2008) Current issues in the management of endome-trial cancer. Elsevier 83(1): 97-112.

6. (2005) American College of Obstetricians and Gynecologists, ACOG practice bulletin, clinical management guidelines for obstetri-ciangynecologists, number 65, August 2005: management of endometrial cancer. Obstet Gynecol 106(2): 413-425.

7. Ravo M, Cordella A, Rinaldi A, Bruno G, Alexandrova E, et al. (2015) Small non-coding RNA deregulation in endometrial carcinogenesis. Oncotarget 6(7): 4677

8. Troisi J, Sarno L, Landolfi A, Scala G, Martinelli P, et al. (2018) Metabolomic Signature of Endometrial Cancer. J Proteome Res 17(2): 804-812.

9. Nagle C, Crosbie E, Brand A, Obermair A, Oehler M, et al. (2018) The association between diabetes, comorbidities, body mass index and allcause and cause-specific mortality among women with endometrial cancer. Gynecologic oncology 150(1): 99-105.

10.Ziel HK, Finkle WD (1975) Increased risk of endometrial carcinoma among users of conjugated estrogens. New England journal of medicine 293: 1167-1170.

11.Jick SS, Walker AM, Jick H (1993) Estrogens, progesterone, and endometrial cancer. Epidemiology 4(1): 20-24.

12. Van Leeuwen F, Benraadt J, Coebergh JW, Kiemeney B, Gimbrère C, et al. (1994) Risk of endometrial cancer after tamoxifen treatment of breast cancer. The Lancet 343(8895): 448-452.

13. Fisher B, Costantino JP, Redmond CK, Fisher ER, Wickerham DL, et al. (1994) Endometrial can-cer in tamoxifen-treated breast cancer patients: findings from the National Surgical Adjuvant Breast and Bowel Project (NSABP) B-14. JNCI Journal of the National Cancer Institute 86(7): 527537.

14. Lynch HT, Lynch J, Conway T, Watson P, Coleman RL (1994) Familial aggregation of carcinoma of the endometrium. American Journal of Obstetrics \& Gynecology 171(1): 24-27.

15. Lu KH, Schorge JO, Rodabaugh KJ, Daniels MS, Sun CC, et al. (2007) Prospective determination of prevalence of lynch syndrome in young women with endometrial cancer. Journal of Clinical Oncology 25(33): 5158-5164.

16. Nead KT, Sharp SJ, Thompson DJ, Painter JN, Savage DB, et al. (2015) Evidence of a causal association between insulinemia and endometrial cancer: a Mendelian randomization analysis. JNCI Journal of the National Cancer Institute 107(9): djv178.

17. Aghajanova L, Giudice L (2011) Effect of bisphenol A on human endometrial stromal fibroblasts in vitro. Reproductive biomedicine online 22(3): 249-256.

18. Hiroi H, Tsutsumi O, Takeuchi T, Momodea M, Ikezuki Y, et al. (2004) Differences in serum bi-sphenol a concentrations in premenopausal normal women and women with endometrial hyperplasia. Endocrine journal 51(6): 595-600. 
19. Pollock T (2014) Presence and bioavailability of bisphenol A in the uterus of rats and mice following single and repeated dietary administration at low doses. Reproductive Toxicology 49: 145-154.

20. Diamanti Kandarakis E, Bourguignon JP, Giudice LC, Hauser R, Prins GS, et al. (2009) Endo-crine-disrupting chemicals: an Endocrine Society scientific statement. Endocrine reviews 30(4): 293-342.

21. Chianese R, Troisi J, Richards S, Scafuro M, Fasano S, et al. (2018) Bisphenol A in Reproduc-tion: Epigenetic Effects. Curr Med Chem 25(6) 748-770.

22. Guida M, Troisi J, Ciccone C, Granozio G, Cosimato C, et al. (2015) Mutation Research/Fundamental and Molecular Mechanisms of Mutagene sis 774: 33-39.

23. Acconcia F, Pallottini V, Marino M (2015) Molecular mechanisms of action of BPA. Dose response 13(4): 1559325815610582.

24. Chou WC, Lee PH, Tan YY, Lin HC, Yang CW, et al. (2017) An integrative transcriptomic analysis reveals bisphenol A exposure-induced dysregulation of microRNA expression in human endometrial cells. Toxicology in Vitro 41: 133-142.

25. Helmestam M, Davey E, Stavreus Evers A, Olovsson M (2014) Bisphenol A affects human endometrial endothelial cell angiogenic activity in vitro. Reproductive Toxicology 46: 69-76.

26. Troisi J, Giugliano L, D’Antonio A, Viggiano A, Meccariello R, et al. (2018) Pla-cental Vascularization and Apoptosis in Rats Orally Exposed to Low Doses of Bisphenol A. Open Journal of Obstetrics and Gy-necology 8(11): 958.

27. Troisi J, Mikelson C, Richards S, Symes S, Adair D, et al. (2014) Placental concentrations of bisphenol A and birth weight from births in the Southeastern U.S. Placenta 35(11): 947-952.

28. Yaguchi T (2018) The endocrine disruptor bisphenol A promotes nuclear ERRy translocation, facilitating cell proliferation of Grade I endometrial cancer cells via EGF-dependent and EGF-independent pathways. Molecular and cellular biochemistry 452(1-2):41-50.

29. Chun TY, Gorski J (2000) High concentrations of bisphenol A induce cell growth and prolactin secretion in an estrogen-responsive pituitary tumor cell line. Toxicology and applied pharmacology 162(3): 161-165.

30. (2008) Scientific Opinion of the Panel on Food additives, Flavourings, Processing aids and Materials in Contact with Food (AFC) Toxi-cokinetics of Bisphenol A - Scientific Opinion of the Panel on Food additives, Flavourings, Processing aids and Materials in Contact with Food (AFC). EFSA Journal 6: 759.

\section{ISSN: 2574-1241}

\section{DOI: 10.26717/BJSTR.2019.21.003641}

\section{Laura Sarno. Biomed J Sci \& Tech Res}

This work is licensed under Creative Commons Attribution 4.0 License

Submission Link: https://biomedres.us/submit-manuscript.php
31. Schönfelder G, Wittfoht W, Hopp H, Talsness CE, Paul M, et al. (2002) Parent bisphenol A accumulation in the human maternal-fetal-placental unit. Environmental health perspectives 110: A703.

32. Zaino RJ (2009) FIGO staging of endometrial adenocarcinoma: a critical review and proposal. Int J Gynecol Pathol 28(1): 1-9.

33. Kosarac I, Kubwabo C, Lalonde K, Foster W (2012) A novel method for the quantitative determination of free and conjugated bisphenol $\mathrm{A}$ in human maternal and umbilical cord blood serum using a two-step solid phase extraction and gas chromatog-raphy/tandem mass spectrometry. Journal of Chromatography B 898: 90-94

34. Aldad TS, Rahmani N, Leranth C, Taylor HS (2011) Bisphenol-A exposure alters endometrial progesterone receptor expression in the nonhuman primate. Fertility and sterility 96(1): 175-179.

35. Shafiee MN, Seedhouse C, Mongan N, Chapman C, Deen S, et al. (2016) Up-regulation of genes involved in the insulin signalling pathway (IGF1, PTEN and IGFBP1) in the endometrium may link polycystic ovarian syndrome and endome-trial cancer. Mol Cell Endocrinol 424: 94-101.

36. Han TS, Lean ME (2016) A clinical perspective of obesity, metabolic syndrome and cardiovascular disease. JRSM Cardiovasc Dis 5: 2048004016633371.

37. Dickerson SM, Gore AC (2007) Estrogenic environmental endocrinedisrupting chemical effects on reproductive neuroendocrine function and dysfunction across the life cycle. Rev Endocr Metab Disord 8(2): 143-159.

38. Fowler PA, Bellingham M, Sinclair KD, Evans NP, Pocar P, et al. (2012) Impact of endocrine-disrupting compounds (EDCs) on female reproductive health. Mol Cell Endocrinol 355(2): 231-239.

39. Rich AL, Phipps LM, Tiwari S, Rudraraju H, Dokpesi PO (2016) The Increasing Prevalence in Intersex Variation from Toxico-logical Dysregulation in Fetal Reproductive Tissue Differentiation and Development by Endocrine-Disrupting Chemicals. En-viron Health Insights 10: 163-171.

40. Mallozzi M, Leone C, Manurita F, Bellati F, Caserta D (2017) Endocrine Disrupting Chemicals and Endometrial Cancer: An Over-view of Recent Laboratory Evidence and Epidemiological Studies. Int J Environ Res Public Health 14(3): pii: E334.

41. Kuiper GG, Carlsson B, Grandien K, Enmark E, Haggblad J, et al. (1997) Comparison of the ligand binding specificity and transcript tissue distribution of estrogen receptors alpha and beta. Endocrinology 138(3): 863-870.

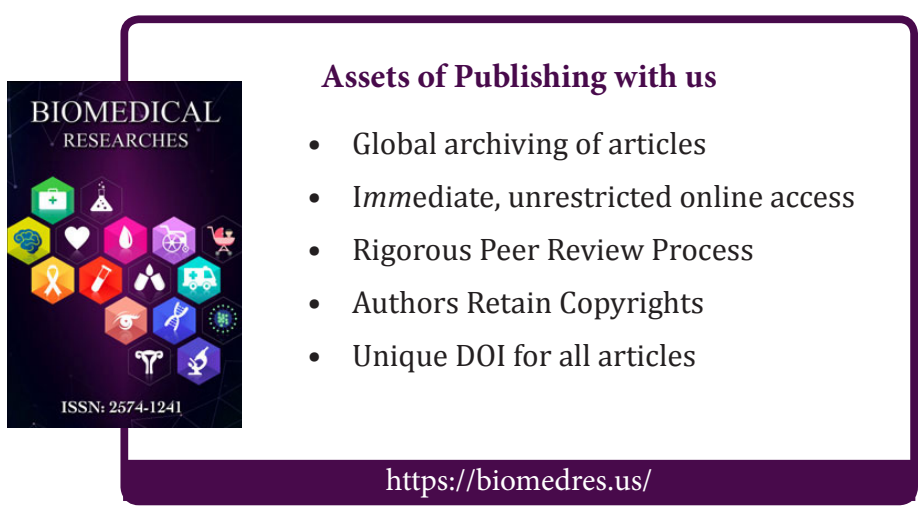

